\title{
Site-specific environmental quality criteria for survival and growth of farmed abalone exposed to zinc
}

\author{
Chung-Min Liao*, Berry Yun-Hua Chou \\ Ecotoxicological Modeling Center, Department of Bioenvironmental Systems Engineering, National Taiwan University, Taipei, \\ 10617 Taiwan, Republic of China
}

Received 8 December 2004; received in revised form 21 January 2005; accepted 2 February 2005

\begin{abstract}
We develop a simple predictive environmental quality criteria (EQC) model for the survival and growth of farmed abalone Haliotis diversicolor supertexta exposed to waterborne zinc $(\mathrm{Zn})$ based on a probabilistic internal effect concentration (IEC)-based modeling framework. We couple a first-order two-compartment bioaccumulation model and a reconstructed dose-response profile based on a three-parameter Hill equation model associated with a field bioaccumulation study to form a probabilistic model to determine acute and chronic EQC. The acute EQC (a-EQC) is predicted from IECs and a field-derived bioaccumulation factors, whereas a statistical procedure with an acute-to-chronic value is used to derive chronic EQC (c-EQC) based on bioaccumulation. Field bioaccumulation study demonstrates a linear relationship between water and tissue $\mathrm{Zn}$ concentrations in abalone and algae. Our model, designed for simplicity and theoretical insight, yields explicit mathematical results through a probabilistic analysis to capture EQC modeling methodology in a more realistic way by analyzing computationally through Monte Carlo simulations. Here we show that the median a-EQC ranges from 0.34-0.39 $\mu \mathrm{g} \mathrm{ml}^{-1}$, whereas the median c-EQC is $0.04-0.05 \mu \mathrm{g} \mathrm{ml}^{-1}$ for selected abalone farms. We believe that this probabilistic EQC modeling framework is an effective method for conceptualizing a public policy decision vis-à-vis establishing a site-specific acceptable acute and chronic EQC for better management and restoration of the rapidly degrading aquacultural ecosystems.
\end{abstract}

(c) 2005 Elsevier B.V. All rights reserved.

Keywords: Abalone; Site-specific environmental quality criteria; Probabilistic; Risk; Toxicity; Zinc

* Corresponding author. Tel.: +88622363 4512; fax: +8862 23626433.

E-mail address: cmliao@ntu.edu.tw (C.-M. Liao).

\section{Introduction}

Richardson (2001) and Wang and Ke (2002) have shown that zinc $(\mathrm{Zn})$ was found in high level (50$120 \mathrm{~g} \mathrm{~g}^{-1}$ dry wt) in the tissues of gastropods. Lin and Liao (1999) and Liao et al. (2002a) indicated that $\mathrm{Zn}$ has been detected in many abalone farms. 
The average $\mathrm{Zn}$ concentrations in aquaculture waters are reported to range from 60 to $130 \mathrm{ng} \mathrm{ml}^{-1}$ in different areas of Taiwan. Abalone Haliotis diversicolor supertexta is commercially important for aquaculture in Taiwan. $H$. diversicolor supertexta is appreciated for their delicacy and high market value. Aquaculture of $H$. diversicolor supertexta is therefore a promising business (http://www.fa.gov.tw, 2003). However, the coastal regions of Taiwan where the abalone farms are situated are subjected to polluted discharges from rivers. Conroy et al. (1996) and Knauer et al. (1997) indicated that if $\mathrm{Zn}$ levels are elevated, toxicity can occur and can have severe effects on the health of abalone, which will reduce market prices and cause closure of abalone farms. The mechanisms of $\mathrm{Zn}$ toxicity involved in the threatening of survival and the inhibition of growth to abalone remain unknown.

US EPA (1995) indicated that environmental quality criteria $(\mathrm{EQC})$ play a pivotal role in protecting ecosystems from undesirable effects of chemicals as it is an essential part of both source- and effectsoriented management for chemical substances. Janssen et al. (2000) and Bergman and Dorward-King (1997) pointed out that neither total nor dissolved aqueous metal concentrations are good predictors of metal bioavailability and toxicity and are inadequate to accurately assess the potential impact of metals on the ecological quality of ecosystems. Rather than develop a single-value waterborne metal concentration for establishing the water quality criteria, it is better to derive a predictive EQC model that explicitly incorporates the factors controlling bioavailability and bioaccumulation in the aquacultural ecosystems.

In the present work, we develop a systematic and quantitative dose-based framework that takes account of the site-specific water quality characteristics to derive the EQC for the survival and growth of farmed abalone. A major complication in deriving EQC for aquacultural species is the high degree of uncertainty resulting from the lack of dose-response information and the large environmental variability in exposures among individuals (Liao et al., 2003; Liao and Ling, 2004). A better approach would be to explicitly model the uncertainties inherent in the toxicity threshold model for aquatic species in that the output would be a distribution of possible toxicity criteria for the survival and growth of abalone from which the level of conservatism can be predicted, e.g., we can choose an appropriate risk criteria value based on a $10 \%$ probability of exceedence the effect concentration affecting 10\% (IEC10) of sensitive aquatic species as suggested by US EPA (1995).

Suggestions have been made that the IEC5 would be more protective of ecosystem structure and function than IEC10 or IEC50 (Van der Hoeven et al., 1997; Moore and Caux, 1997). Versteeg et al. (1999) and Van der Brink et al. (2002) also suggested that the selection of a hazard external effect concentration (EEC) protecting $95 \%$ of the single-specific sensitivity distribution (i.e., EEC5) appears to provide an appropriate level of protection when compared to multispecies tests or field studies. One reason is that if concentrations of this compound are below the EEC5, more than $95 \%$ of the biological species set considered will not display effects as determined by the chronic toxicity tests. Because $H$. diversicolor supertexta are commercially important and have high market prices in Taiwan aquaculture, we choose IEC5 and EEC5 as the threshold of $\mathrm{Zn}$ toxicity for survival and growth endpoints to derive acute and chronic EQC, respectively.

Because chronic tests are more lengthy and the endpoints are somewhat subjective, it is not surprising that more often chronic and standards are based on the acute-to-chronic ratio (ACR) (US EPA, 1985; Ford, 2001). The ACR is an acute toxicity values measured to its chronic toxicity values, measured under the same experimental conditions. The ACRs are derived on a species-by-species basis, ideally with both the acute and chronic toxicity data developed from the same test. The ACR values are typically greater than one, reflecting the fact that chronic toxicity typically occurs at lower levels than dose acute toxicity. Species mean ACRs ranged from 1.48 in saltwater for the sheepshead minnow (Hughes et al., 1989) to 171.2 in freshwater for the snail Campeloma decisum (Arthur and Leonard, 1970). US EPA (1985) suggested that the ACR approach can be served as the basis of the chronic criteria in that the ACR is the geometric mean of the ratio of acute to chronic values.

Our purpose is to present a probabilistic IEC-based approach to derive a predictive site-specific EQC for 
the survival and growth of farmed abalone exposed to waterborne $\mathrm{Zn}$. We demonstrate its utility by applying it to real abalone farms using the methodology for water quality criteria derivation developed by US EPA (1995) and Traas et al. (2004). The methodology adopted herein is an analysis tool that couples probabilistic submodels of the bioaccumulation process and the dose-response relationship to arrive at a probabilistic EQC model to determine a suitable $\mathrm{Zn}$ toxicity threshold for risk managers who prefer the risk threshold to have a higher or lower level of protection.

\section{Materials and methods}

The dose-based probabilistic site-specific EQC modeling framework is divided into four phases (Fig. 1) and is described in the subsequent sections.

\subsection{Development of a EQC model to relate EQC, IEC5, and EEC5}

The acute EQC (a-EQC, $\mu \mathrm{g} \mathrm{ml}^{-1}$ ) model for the survival protection of farmed abalone exposed to $\mathrm{Zn}$ can be expressed as (Traas et al., 2004),

$\mathrm{a}-\mathrm{EQC}=\frac{\mathrm{IEC} 5}{\mathrm{BAF}_{\mathrm{m}}}$,

where IEC5 is based on mortality as an endpoint where $5 \%$ of the abalone individuals died $\left(\mu \mathrm{g} \mathrm{g}^{-1}\right.$ dry $w t$ ), and $\mathrm{BAF}_{\mathrm{m}}$ is the bioaccumulation factor of abalone $\left(\mathrm{ml} \mathrm{g}^{-1}\right)$. We treat IEC5 and $\mathrm{BAF}_{\mathrm{m}}$ in Eq. (1) probabilistically.

The chronic EQC (c-EQC, $\mu \mathrm{g} \mathrm{ml}^{-1}$ ) (Traas et al., 2004) for the growth protection of farmed abalone can be expressed by introducing the CBR theory (Verhaar et al., 1999; Legierse et al., 1999) that assumes that the effect occurs when the total body burden of an organism reaches a certain threshold level, to relate EEC5 and IEC5 of IEC5 $=$ EEC5 $\times$ $\mathrm{BCF}_{\mathrm{m}}$ as,

$$
\mathrm{c}-\mathrm{EQC}=\frac{\mathrm{EEC} 5}{\mathrm{ACR}}=\frac{\mathrm{IEC} 5}{\mathrm{BCF}_{\mathrm{m}} \mathrm{ACR}}
$$

where EEC5 is based on growth as an endpoint where $5 \%$ of abalone individuals growth inhibited $\left(\mu \mathrm{g} \mathrm{ml}^{-1}\right)$, and $\mathrm{BCF}_{\mathrm{m}}$ is the bioconcentration factor of abalone $\left(\mathrm{ml} \mathrm{g}^{-1}\right)$. ACR is the acute-to-chronic value in that chronic value is usually expressed as a geometric mean of no-observed effect concentration (NOEC, $\mu \mathrm{g} \mathrm{ml}^{-1}$ ) and lowest-observed effect concentration (LOEC, $\mu \mathrm{g} \mathrm{ml}^{-1}$ ), and has a form as (Tsai et al., 2004),

$$
\mathrm{ACR}=\mathrm{LC} 50 / \sqrt{\mathrm{NOEC} \times \mathrm{LOEC}} .
$$

To quantify the influence of uncertainty in EEC5 and ACR on c-EQC, we treat IEC5, BCF ${ }_{\mathrm{m}}$, and ACR in Eq. (2) probabilistically.

\subsection{Derivation of $B A F m$}

Zinc is accumulated in abalone both by dietary (i.e., red algae Gracilaria tenuistipitata var. liui, the major forage for culturing $H$. diversicolor supertexta) and nondietary (i.e., water source) routes. If the dissolved $\mathrm{Zn}$ concentration in water is assumed to be constant, whereas the $\mathrm{Zn}$ concentration in algae is assumed to vary with time, the temporal change of $\mathrm{Zn}$ concentration in abalone could be modeled using a first-order two-compartment bioaccumulation model as,

$$
\frac{\mathrm{d} C_{\mathrm{m}}(t)}{d \mathrm{t}}=\alpha f C_{\mathrm{a}}(t)+k_{1} C_{\mathrm{w}}-\left(k_{2}+k_{2 \mathrm{f}}+g\right) C_{\mathrm{m}}(t),
$$

$\frac{\mathrm{d} C_{\mathrm{a}}(t)}{\mathrm{d} t}=k_{1 \mathrm{a}} C_{\mathrm{w}}-\left(k_{2 \mathrm{a}}+\alpha f+g_{a}\right) C_{\mathrm{a}}(t)$,

where $C_{\mathrm{m}}(t)$ is the time-dependent $\mathrm{Zn}$ concentration in abalone at time $t$ in day ( $\mu \mathrm{g} \mathrm{g}^{-1}$ dry wt), $C_{\mathrm{w}}$ is the dissolved $\mathrm{Zn}$ concentration in water $\left(\mathrm{ng} \mathrm{ml}^{-1}\right.$ ), $C_{\mathrm{a}}(t)$ is the time-dependent $\mathrm{Zn}$ concentration in algae at time $t$ in day ( $\mu \mathrm{g} \mathrm{g}^{-1}$ dry wt), $\alpha$ is the assimilation efficiency of abalone (\%), $f$ is the abalone grazing rate $\left(\mathrm{g} \mathrm{g}^{-1} \mathrm{~d}^{-1}\right), k_{1}$ is the abalone uptake rate of $\mathrm{Zn}\left(\mathrm{ml} \mathrm{g}^{-1} \mathrm{~d}^{-1}\right), k_{2}$ is the abalone depuration rate $\left(\mathrm{d}^{-1}\right), k_{2 \mathrm{f}}$ is the elimination rate 


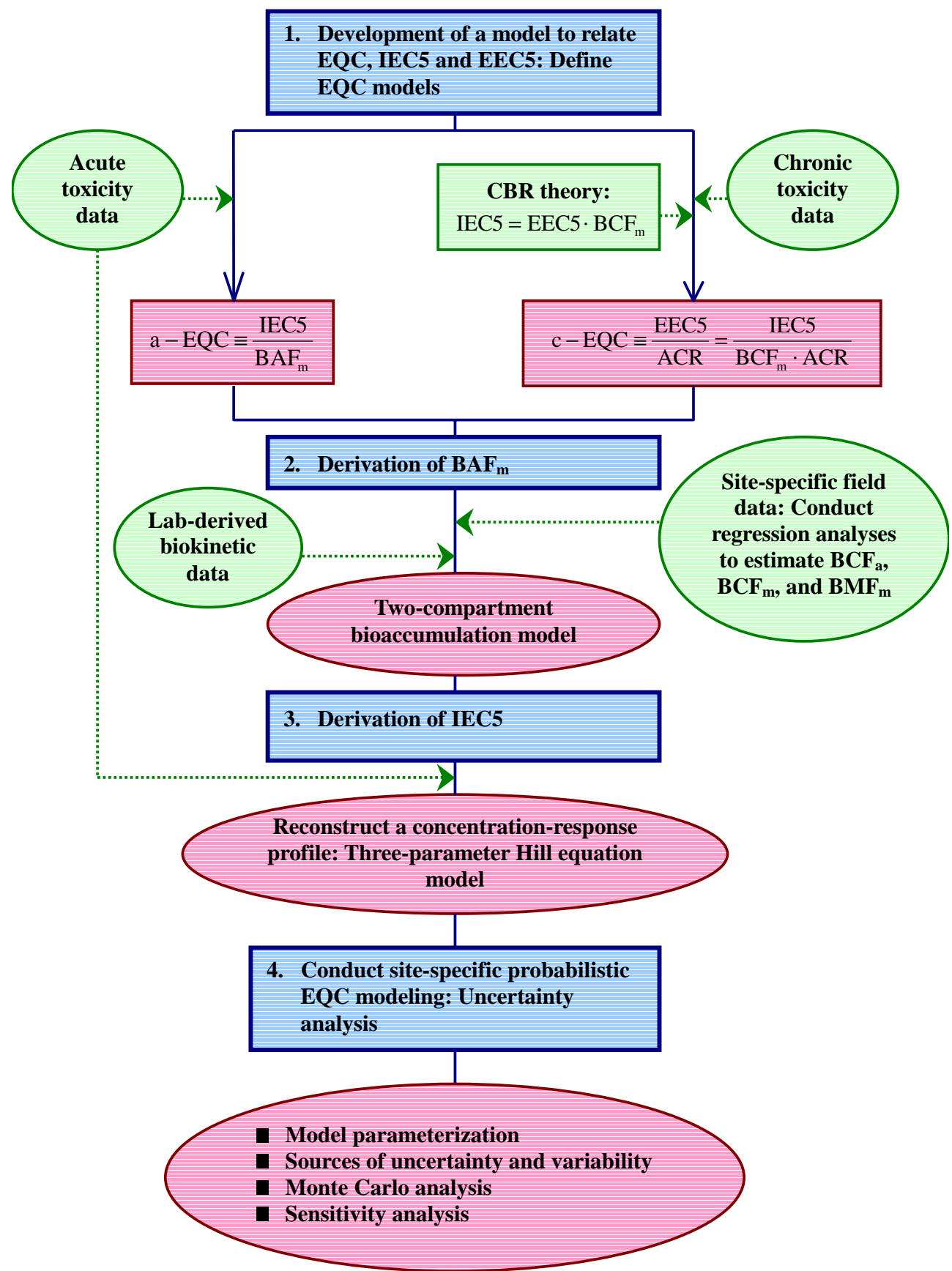

Fig. 1. A conceptual algorithm describing the dose-based probabilistic environmental quality criteria (EQC) modeling framework for survival and growth of farmed abalone exposed to waterborne $\mathrm{Zn}$.

constant for $\mathrm{Zn}$ from food in abalone $\left(\mathrm{d}^{-1}\right), g$ is the abalone growth rate $\left(\mathrm{d}^{-1}\right), k_{2 \mathrm{a}}$ is the algae depuration rate of $\mathrm{Zn}\left(\mathrm{d}^{-1}\right), k_{1 \mathrm{a}}$ is the algae uptake rate of $\mathrm{Zn}\left(\mathrm{ml} \mathrm{g}^{-1} \mathrm{~d}^{-1}\right)$, and $g_{\mathrm{a}}$ is the algae growth rate $\left(\mathrm{d}^{-1}\right)$. Assuming that the initial $\mathrm{Zn}$ concentration is equal to zero in algae and consider the 
steady-state condition in Eq. (4) and solve for $C_{\mathrm{a}}$ gives,

$C_{\mathrm{a}}=\mathrm{BCF}_{\mathrm{a}} C_{\mathrm{w}}$,

where $\mathrm{BCF}_{\mathrm{a}}=k_{1 \mathrm{a}} /\left(k_{2 \mathrm{a}}+\alpha f+g_{\mathrm{a}}\right)$ is the bioconcentration factor of $G$. tenuistipitata var. liui for $\mathrm{Zn}(\mathrm{ml}$ $\mathrm{g}^{-1}$ ). We solve Eq. (3) by substituting Eq. (5) into Eq. (3) and obtain,

$C_{\mathrm{m}}(t)=C_{\mathrm{m}}(t=0) e^{-K_{\mathrm{e}} t}+\frac{K_{\mathrm{u}}}{K_{\mathrm{e}}} C_{\mathrm{w}}\left(1-e^{-K_{\mathrm{e}} t}\right)$,

where $K_{\mathrm{u}}$ and $K_{\mathrm{e}}$ represent the overall uptake and overall elimination rate constants, respectively, and have the form as,

$K_{\mathrm{u}}=k_{1}+\alpha f \mathrm{BCF}_{\mathrm{a}}$,

$K_{\mathrm{e}}=k_{2}+k_{2 \mathrm{f}}+g$.

The $\mathrm{Zn}$ concentration in abalone is calculated as $C_{\mathrm{m}}=\left(K_{\mathrm{u}} / K_{\mathrm{e}}\right) C_{\mathrm{w}}=\mathrm{BAF}_{\mathrm{m}} C_{\mathrm{w}}$ when equilibrium is achieved in Eq. (6) in that we define the bioaccumulation factor of abalone as $\mathrm{BAF}_{\mathrm{m}}=K_{\mathrm{u}} / K_{\mathrm{e}}$ and has the form as,

$\mathrm{BAF}_{\mathrm{m}}=\frac{\mathrm{BCF}_{\mathrm{m}}}{1+\left(k_{2 \mathrm{f}}+g\right) k_{2}^{-1}}+\mathrm{BMF}_{\mathrm{m}} \mathrm{BCF}_{\mathrm{a}}$,

where $\mathrm{BCF}_{\mathrm{m}}$ is the bioconcentration factor of abalone $\left(\mathrm{ml} \mathrm{g}^{-1}\right)$ and $\mathrm{BMF}_{\mathrm{m}}=g_{\mathrm{a}} / K_{\mathrm{e}}$ is the biomagnification factor of abalone $\left(\mathrm{g} \mathrm{g}^{-1}\right) . \mathrm{BCF}_{\mathrm{a}}, \mathrm{BCF}_{\mathrm{m}}$, and $\mathrm{BMF}_{\mathrm{m}}$ in Eq. (9) can be derived from a field bioaccumulation study.

Eq. (3) describes the gain and loss of $\mathrm{Zn}$ accumulation in abalone featuring constant biokinetic and physiological rates and a constant water concentration. The major processes in Eqs. (3) and (4) include (i) the exchange of $\mathrm{Zn}$ between abalone and dissolved $\mathrm{Zn}$ was modeled as a first-order process with additional $\mathrm{Zn}$ accumulation from ingested algae, (ii) abalone ingests only algae and neglects other suspended particles, bacteria, and detritus uptakes, (iii) tissue concentration of $\mathrm{Zn}$ per unit biomass of abalone increases as a result of direct uptake from water and through assimilation of algae, and (iv) tissue concentration tends to decrease as a result of elimination from the whole body and growth dilution.

\subsubsection{Field bioaccumulation study}

We conducted a field bioaccumulation study to determine $\mathrm{BCF}_{\mathrm{a}}, \mathrm{BCF}_{\mathrm{m}}$, and $\mathrm{BMF}_{\mathrm{m}}$ based on the field data obtained from real abalone farms. The most important farming areas for the production of abalone $H$. diversicolor supertexta are located at Toucheng, Kouhu, and Anping, respectively, on the north, west, and south coastal areas of Taiwan region. All the abalone farms use seawater from polluted coastal areas. We selected 3 abalone farms for each location mentioned above to collect the samples on the abalone, the red algae G. Tenuistipitata var. liui, and ambient water. Three abalone, three algae, and three $500 \mathrm{ml}$ water samples per farm were collected. The abalone and algal samples initially were washed in seawater to remove epiphytes and kept at $4{ }^{\circ} \mathrm{C}$ during transfer to the lab at Ecotoxicological Modeling Center. The water samples were fixed by adding 5 $\mathrm{ml} 1 \mathrm{~N} \mathrm{HNO}_{3}$. The algae and shucked abalone were freeze-dried overnight and then ground into a fine powder in a grinder (Tai-Hsiang S36-89). $500 \mathrm{mg}$ portions of the ground samples were digested in $10 \mathrm{ml}$ concentrated $\mathrm{HNO}_{3}$ (65 wt.\%) overnight at room temperature.

A Perkin-Elmer Model 5100PC atomic absorption spectrometer (Shelton, CT, USA) equipped with an HGA-300 graphite furnace atomizer was used to analyze $\mathrm{Zn}$. The detection limit is $5 \mu \mathrm{g} \mathrm{Zn} \mathrm{l^{-1 }}$ water and $0.5 \mu \mathrm{g} \mathrm{Zn}^{-1}$ tissue. External quality control was achieved by digesting and analyzing identical amounts of dehydrated ( $90 \%$ water) standard reference materials (DORM-2 Dogfish Liver-2-oganic matrix, provided by the NRC-CNRC, National Research Council of Canada). Recovery rates ranged from $95-97 \%$. We employed Statistica ${ }^{\circledR}$ software (StatSoft, Tulsa, OK, USA) to perform regression analysis and statistical analysis (analysis of variance and Student $t$ test). Statistical significance was judged by $p<0.05$.

\subsection{Derivation of IEC5}

We employ an empirical three-parameter Hill equation model to fit mortality responses in relation to $\mathrm{Zn}$ whole-body burden in abalone based on published acute toxicity data and the previously established relationship between $\mathrm{Zn}$ tissue residues and mortality effects in abalone by Liao et al. 
(2002a,b). In fitting the Hill equation model to the observed mortality for specific-interval acute toxicity data, the dose-response profile can be expressed as (Liao et al., 2002a,b),

$$
M=\frac{100 \times C_{\mathrm{w}}^{3.70}}{(24-\mathrm{h} \mathrm{LC} 50)^{3.70}+C_{\mathrm{w}}^{3.70}},
$$

where $M$ is the mortality (\%), 24-h LC50 is the $24-\mathrm{h}$ median lethal concentration $\left(\mathrm{mg} \mathrm{l}^{-1}\right.$ ), and the exponent 3.70 is an average value of the fitted Hill coefficient, indicating the number of ligand molecules that are required to bind to the receptor in order to produce a functional effect (Weiss, 1997). Here the averaged Hill coefficient larger than one indicates positive cooperativity.

We appropriately transform Eq. (10) to an IECbased dose-response relationship using the Hill model framework to predict the response as (Liao et al., 2002a,b),

$$
\begin{aligned}
M & =\frac{100 \times C_{\mathrm{m}}^{3.70}}{(\mathrm{IEC} 50)^{3.70}+C_{\mathrm{m}}^{3.70}} \\
& =\frac{100 \times C_{\mathrm{m}}^{3.70}}{\left(\mathrm{BCF}_{\mathrm{m}} \mathrm{LC} 50(\infty)\right)^{3.70}+C_{\mathrm{m}}^{3.70}},
\end{aligned}
$$

where IEC 50 based on the site of action that cause $50 \%$ mortality of abalone individuals $\left(\mu \mathrm{g} \mathrm{g}^{-1}\right.$ dry wt) and $\operatorname{LC} 50(\infty)$ is the incipient value of LC50 $\left(\mathrm{mg} \mathrm{l}^{-1}\right)$. We treated $\mathrm{BCF}_{\mathrm{m}}$ and $\mathrm{LC} 50(\infty)$ in Eq. (11) probabilistically. Applying the Hill equation model, the cumulative distribution function (cdf) of predicted mortality function for a given tissue $\mathrm{Zn}$ concentration, $F(M \mid C)$, could be expressed symbolically as a conditional cdf,

$F(M \mid C)=\Phi\left(\frac{100 \times C^{3.70}}{\left(\mathrm{BCF}_{\mathrm{m}} \mathrm{LC} 50(\infty)\right)^{3.70}+C^{3.70}}\right)$,

where $C$ is the given $\mathrm{Zn}$ concentration in abalone $(\mu \mathrm{g}$ $\mathrm{g}^{-1}$ dry wt) and $\Phi(\bullet)$ is the cumulative standard normal distribution. We use Eq. (12) to estimate the distribution of IEC5.

\subsection{Uncertainty analysis}

\subsubsection{Model parameterization}

Current literature is reviewed to develop probability distributions for the random variables appearing in the bioaccumulation model and the dose-response model adopted. Source data of input variables in EQC modeling would be obtained from published studies by Chen (1984, 1989), Lee et al. (1996), Lin and Liao (1999), Chen and Lee (1999) and Liao et al. (2002a,b), and Liao et al. (2003). Data were sorted by reported statistical measure, e.g., mean, standard deviation, standard error, etc. There are multiple sources of variability and uncertainty to be considered during distribution development for model input variables from measured values. Therefore, data are log-transformed when necessary to meet the assumptions of statistical normality. We use the Statistica ${ }^{\circledR}$ software package to analyze data and distribution parameters. We use the chi-square $\left(\chi^{2}\right)$ and the KolmogorovSmirnov (K-S) statistics to optimize the goodness-offit of distributions. The implemented parameter probability distributions are summarized in Table 1 and will be described in the subsequent sections.

2.4.1.1. Biokinetic parameters: $k 2, k 2 f, g, B C F a$, $B M F m, B C F m$. Distributions are fitted to polled labderived data of $k_{2}$ and $k_{2 \mathrm{f}}$ obtained from different sources and the selected lognormal distributions have the acceptable $\chi^{2}$ and $\mathrm{K}-\mathrm{S}$ fits in that optimizations using either statistics yield geometric mean (gm) and geometric standard deviation (gsd) (Table 1). The field-derived parameters $\left(\mathrm{BCF}_{\mathrm{a}}, \mathrm{BMF}_{\mathrm{m}}, \mathrm{BCF}_{\mathrm{m}}\right)$ could be obtained by performing a linear regression analysis to derive the relationships among algae $\mathrm{Zn}$ concentration $\left(C_{\mathrm{a}}, \mu \mathrm{g} \mathrm{g}^{-1}\right.$ dry $\left.\mathrm{wt}\right)$, abalone $\mathrm{Zn}$ concentration $\left(C_{\mathrm{m}}, \mu \mathrm{g} \mathrm{g}^{-1}\right.$ dry $\left.\mathrm{wt}\right)$, and waterborne $\mathrm{Zn}$ concentration $\left(C_{\mathrm{w}}, \mu \mathrm{g} \mathrm{ml}^{-1}\right)$ based on the field bioaccumulation study followed the definitions of $\mathrm{BCF}_{\mathrm{a}}=C_{\mathrm{a}}$ / $C_{\mathrm{w}}, \mathrm{BCF}_{\mathrm{m}}=C_{\mathrm{m}} / C_{\mathrm{w}}$, and $\mathrm{BMF}_{\mathrm{m}}=C_{\mathrm{a}} / C_{\mathrm{m}}$ in that $C_{\mathrm{w}}$ is treated probabilistically.

2.4.1.2. Geochemical parameter: $C w$. Distributions of water $\mathrm{Zn}$ levels in abalone farm $\left(C_{\mathrm{w}}\right)$ are fitted to the polled field observations obtained from three designated abalone farms and the selected lognormal distributions have the optimal $\mathrm{K}-\mathrm{S}$ and $\chi^{2}$ goodnessof-fit (Table 1).

2.4.1.3. Dose-response parameter: LC50( $\infty)$. In applying dose-response relationships derived from experimental study, we must consider the limitations of the data and account for the inherent uncertainty 
Table 1

Input parameters for probabilistic EQC modeling framework

\begin{tabular}{|c|c|c|}
\hline Parameters & Uncertainty/variability & Distribution \\
\hline \multicolumn{3}{|c|}{ Biokinetic parameters } \\
\hline $\mathrm{BCF}_{\mathrm{m}}\left(\mu \mathrm{g} \mathrm{m}^{-1}\right)$ & $\mathrm{U}$ & \\
\hline Toucheng & & $\operatorname{LN}(738.68,1.05)^{\mathrm{a}}$ \\
\hline Kouhu & & $\mathrm{LN}(927.77,1.20)$ \\
\hline Anping & & $\mathrm{LN}(913.70,1.21)$ \\
\hline $\mathrm{BCF}_{\mathrm{a}}\left(\mu \mathrm{g} \mathrm{ml}^{-1}\right)$ & $\mathrm{U}$ & \\
\hline Toucheng & & $\mathrm{LN}(609.48,1.05)$ \\
\hline Kouhu & & $\mathrm{LN}(420.90,1.40)$ \\
\hline Anping & & $\mathrm{LN}(439.96,1.38)$ \\
\hline $\mathrm{BMF}_{\mathrm{m}}\left(\mu \mathrm{g} \mathrm{ml}^{-1}\right)$ & $\mathrm{U}$ & \\
\hline Toucheng & & $\mathrm{LN}(1.15,1.14)$ \\
\hline Kouhu & & $\mathrm{LN}(2.36,2.04)$ \\
\hline Anping & & $\mathrm{LN}(2.17,1.97)$ \\
\hline
\end{tabular}

Lab-derived parameters

$k_{2}\left(\mathrm{~d}^{-1}\right) \quad \mathrm{U}$

$k_{2 \mathrm{f}}\left(\mathrm{d}^{-1}\right) \quad \mathrm{U}$

$\operatorname{LN}(0.390,4.746)$

$\mathrm{LN}(0.602,1.530)$

c-EQC model parameter

ACR

$\mathrm{U}$

$\mathrm{LN}(13.57,1.14)$

Geochemical parameters

$C_{\mathrm{w}}\left(\mu \mathrm{g} \mathrm{ml}^{-1}\right) \quad \mathrm{U}$

Toucheng

$\mathrm{LN}(0.127,1.310)$

Kouhu

Anping

LN $(0.055,1.700)$

LN $(0.059,1.770)$

Dose-response parameters

$\mathrm{LC} 50(\infty)\left(\mathrm{mg} \mathrm{1}^{-1}\right) \quad \mathrm{U}$

$\mathrm{N}(1.2,0.158)^{\mathrm{b}}$

${ }^{a}$ Lognormal distribution with a geometric mean and a geometric standard deviation.

${ }^{\mathrm{b}}$ Normal distribution with a mean and a standard deviation.

that arises from a number of sources, including the limited number of observations and limited sample size within treatment sets. To account this uncertainty, we construct distributions for the input variables of $\mathrm{BCF}_{\mathrm{m}}$ and $\mathrm{LC} 50(\infty)$ of Hill dose-response function in Eq. (11). We determine a normal distributions to $\operatorname{LC} 50(\infty)$ (Table 1), and incorporate the distributions into the Monte Carlo simulation to obtain 2.5th- and 97.5th-percentiles as the $95 \%$ confidence interval (CI) for reconstructed dose-response profile. Uncertainty and/or variability are not considered for the reported Hill coefficient since the Hill coefficient from the published study is reported only as an average value.

2.4.1.4. $A C R$. In order to derive the ACR value as defined in Eq. (2b), we adopted the acute toxicity value from Liao and Lin (2001) from which the acute endpoint was described by 72-h LC50 with a value of $1.2 \pm 0.158$ (mean \pm S.D.). The chronic toxicity value is estimated to be 0.088 that is calculated from the geometric mean of NOEC and LOEC values obtained from Tsai et al. (2004). Then, the ACR value can be calculated by Eq. (2b) in that we consider 72-h LC50 value as a normal distribution as $N(1.2,0.158)$, resulting in the $\mathrm{ACR}=N(13.69,1.8)$ by 5000 iterations of Monte Carlo simulation. We appropriately log-transformed the ACR value to a lognormal distribution with a geometric mean of 13.57 and a geometric standard deviation of 1.14 (Table 1).

\subsubsection{Monte Carlo analysis}

Uncertainty arises from estimation of both exposure and effects. In order to quantify this uncertainty and its impact on the estimation of expected risk, we implement a Monte Carlo simulation that includes input distributions for the parameters of the derived doseresponse function as well as for estimated exposure parameters. To test the convergence and the stability of the numerical output, we perform independent runs at 1000,4000 , and 5000 iterations with each parameter sampled independently from the appropriate distribution at the start of each replicate. Largely because of limitations in the data used to derive model parameters, inputs were assumed to be independently. The result shows that 5000 iterations are sufficient to ensure the stability of results. Sensitivity analysis identifies the most significant parameters that are included in the uncertainty and variability analysis. The sensitivity of each variable relative to one another is assessed by calculating rank correlation coefficients between each input and output during simulations and then estimating each input contribution to the output variance by squaring the output variance and normalizing to $100 \%$. The Monte Carlo simulation is implemented using Crystal Ball ${ }^{\circledR}$ software (Version 2000.2, Decisioneering, Colorado, USA).

\section{Results}

\subsection{Field-derived bioaccumulation factors}

The correlations of $\mathrm{Zn}$ concentrations in abalone, algae, and water are significant (Fig. 2) in that variances of $\mathrm{Zn}$ concentrations in abalone, algae, 

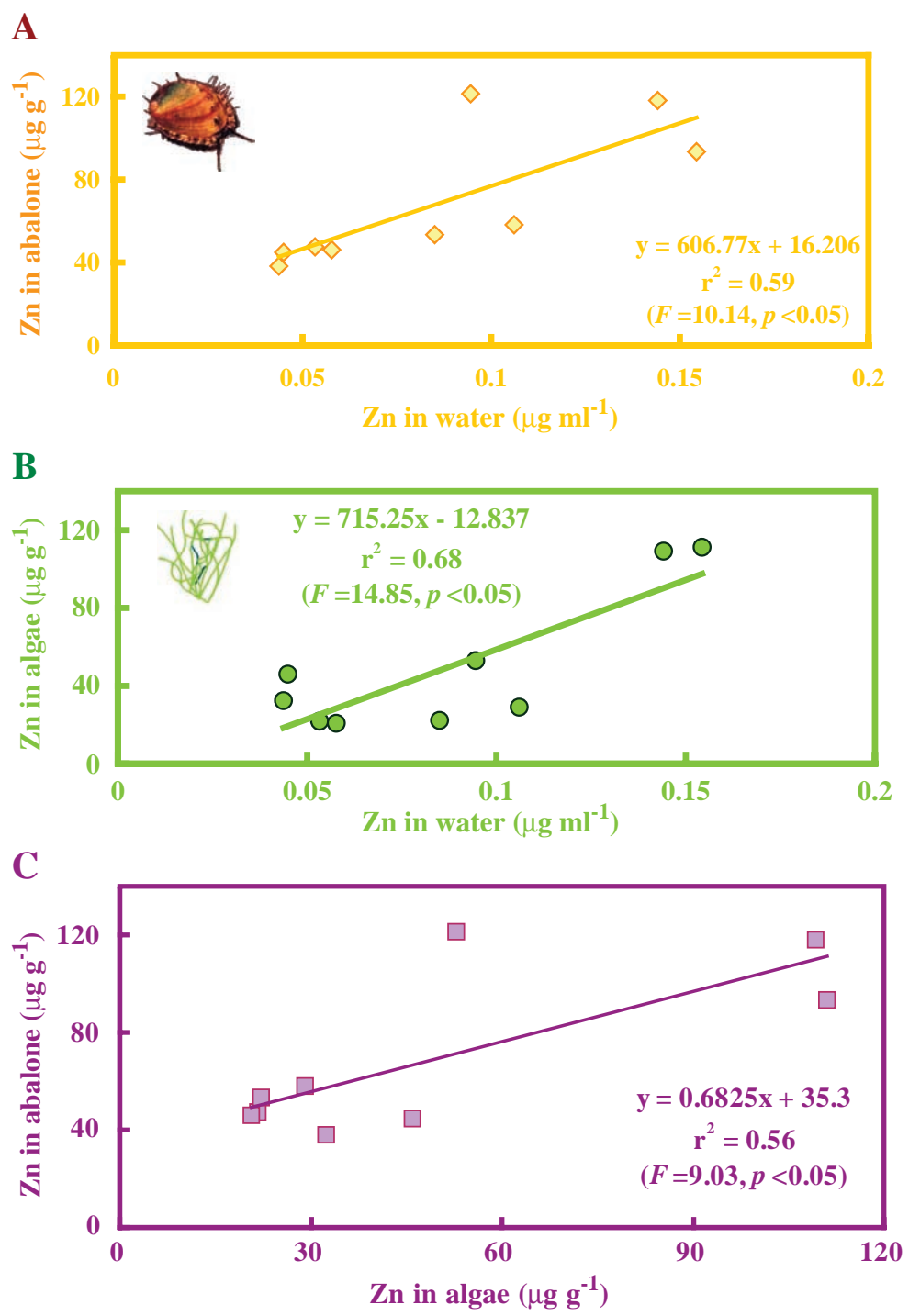

Fig. 2. Results of the field accumulation study showing $\mathrm{Zn}$ levels in (A) H. diversicolor supertexta and in (B) G. tenuistipitata var. liui as a function of $\mathrm{Zn}$ concentration in water as well as (C) Zn levels in abalone as a function of Zn levels in algae G. tenuistipitata var. liui.

and water were tested for homogeneity using $F$-test and values of $\mathrm{Zn}$ concentration were than compared using the appropriate $t$ test. Fig. 2 also demonstrates that $\mathrm{Zn}$ levels in abalone and algae increased with that in water, whereas $\mathrm{Zn}$ level in abalone increased also with that in algae. Eq. (6) reveals that $\mathrm{Zn}$ level in abalone $\left(C_{\mathrm{m}}\right)$ is a linear function of water $\mathrm{Zn}$ content $\left(C_{\mathrm{w}}\right)$ with all other parameters being constant within a given experiment. Consequently, a straight line can describe the model fits for each of the experimental units analyzed in this study (Fig. 2). The resulting regression equations for $\mathrm{BCF}_{\mathrm{a}}, \mathrm{BCF}_{\mathrm{m}}$, and $\mathrm{BMF}_{\mathrm{m}}$ can be determined from Fig. 2 as: $\mathrm{BCF}_{\mathrm{a}}=0.715-12.84 \times$ $C_{\mathrm{w}}^{-1} ; \mathrm{BCF}_{\mathrm{m}}=0.61+16.20 \times C_{\mathrm{w}}^{-1}$; and $\mathrm{BMF}_{\mathrm{m}}=$ $0.683+35.30\left(0.72 \times C_{\mathrm{w}}-12.84\right)^{-1}$. Table 1 gives the lognormal distributions of site-specific $\mathrm{BCF}_{\mathrm{a}}$, $\mathrm{BCF}_{\mathrm{m}}$, and $\mathrm{BMF}_{\mathrm{m}}$. Fig. 3 shows the probability density function (pdf) of the site-specific $\mathrm{BAF}_{\mathrm{m}}$ subject to the given site-specific pdfs of water $\mathrm{Zn}$ level for three selected abalone farms. The field 


$$
\mathrm{C}_{\mathrm{w}}\left(\mu \mathrm{g} \mathrm{ml}^{-1}\right) \quad \quad \mathrm{BAF}_{\mathrm{m}}\left(\mathrm{ml} \mathrm{g}^{-1}\right)
$$
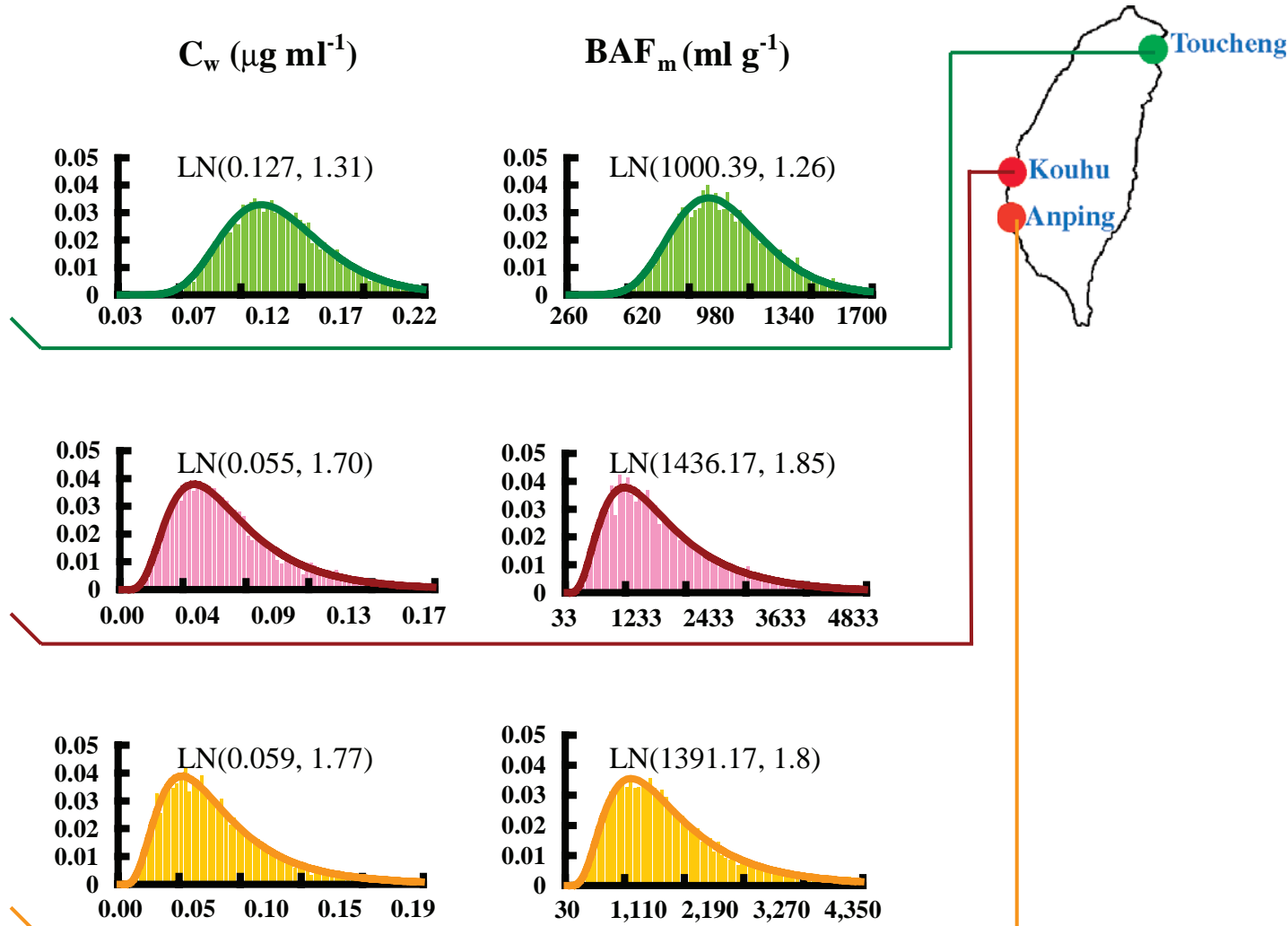

Fig. 3. Probability density functions (pdfs) of model-derived bioaccumulation factor of abalone $\left(\mathrm{BAF}_{\mathrm{m}}\right)$ subject to site-specific pdfs of water $\mathrm{Zn}$ level $\left(C_{\mathrm{w}}\right)$ for three selected abalone farms. $\operatorname{LN}(\alpha, \beta)$ indicates the lognormal distribution with a geometric mean $\alpha$ and a geometric standard deviation $\beta$.

bioaccumulation study also demonstrates an inverse relationship between waterborne exposure concentration and corresponding bioaccumulation factor that is frequently observed for metals (Adams et al., 2000; McGeer et al., 2003).

\subsection{Site-specific IEC5 for Zn intrinsic toxicity}

The Hill equation model and a 5000 iteration of Monte Carlo simulation provided an adequate fit to the data $\left(\chi^{2}\right.$ goodness-of-fit, $P>0.5$ ) (Fig. 4A-C). In the present work, we employ the more restricted regulatory endpoint IEC5 as a surrogate threshold in probabilistic EQC modeling. We appropriately log-transformed the site-specific IEC5 values for three designated abalone farms and results in lognormal distributions of Toucheng: LN(387.58 $\mu \mathrm{g} \mathrm{g}^{-1}$ dry wt, 1.15), Kouhu: LN(493.98 $\mu \mathrm{g}$ $\mathrm{g}^{-1}$ dry wt, 1.23), and Anping: $\mathrm{LN}\left(486.82 \mu \mathrm{g} \mathrm{g}^{-1}\right.$ dry wt, 1.26) in that $\mathrm{LN}(\mathrm{gm}, \mathrm{gsd})$ denotes lognormal distribution with a geometric mean (gm) and a geometric standard deviation (gsd) (Fig. 4D-F).

\subsection{Environmental quality criteria}

The site-specific a-EQC is determined as the quotients of the IEC5 and BAF of abalone (Eq. (1)) for three selected abalone farms (Fig. 5A), whereas the sitespecific c-EQC values are calculated from the quotient of CBR-based IEC5 and BCF of abalone linked with an acute to chronic effect (Eq. (2a)) (Fig. 5B). The median a-EQC are $0.39,0.34$, and $0.36 \mu \mathrm{g} \mathrm{ml}^{-1}$, respectively, for Toucheng, Kouhu, and Anping. The site-specific median a-EQC values generally are lower than the $96-\mathrm{h} \mathrm{LC50}$ value of $1.1 \mu \mathrm{g} \mathrm{ml}^{-1}$ with $95 \%$ CI: $0.83-1.59 \mu \mathrm{g} \mathrm{ml}^{-1}$ (Liao et al., 2002b) yet fall within the uncertainty of the a-EQC of abalone farms of Kouhu and Anping (Fig. 5A). The median sitespecific c-EQC values for Toucheng, Kouhu, and 


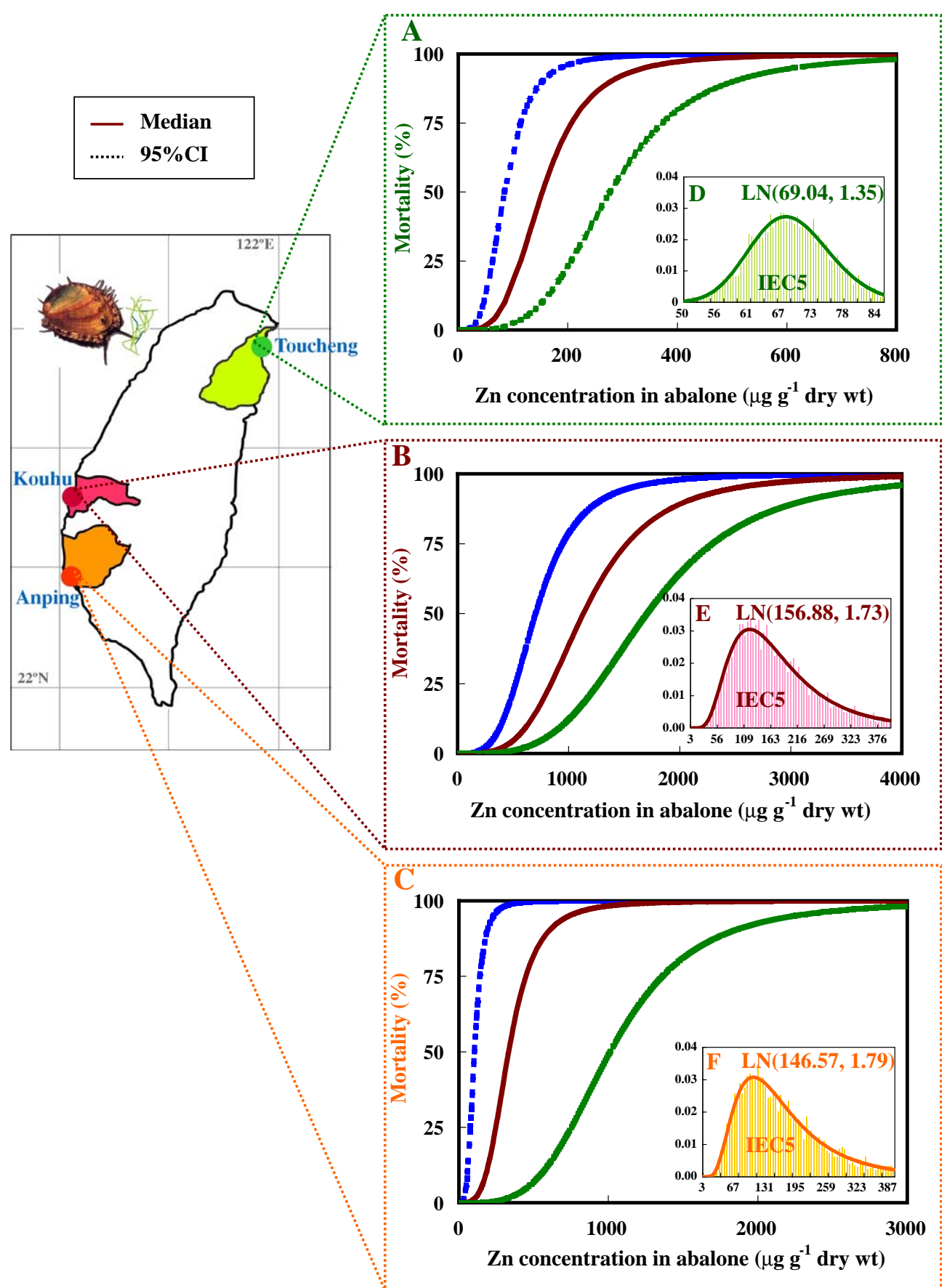

Fig. 4. (A-C) Reconstructed site-specific concentration-response profiles with $95 \%$ CI showing the relationship between abalone mortality and $\mathrm{Zn}$ level in abalone for three selected abalone farms associated with (D-F) the probability density functions of site-specific internal effect concentration that causes $5 \%$ mortality of abalone (IEC5) in that IEC5 has a lognormal distribution. 


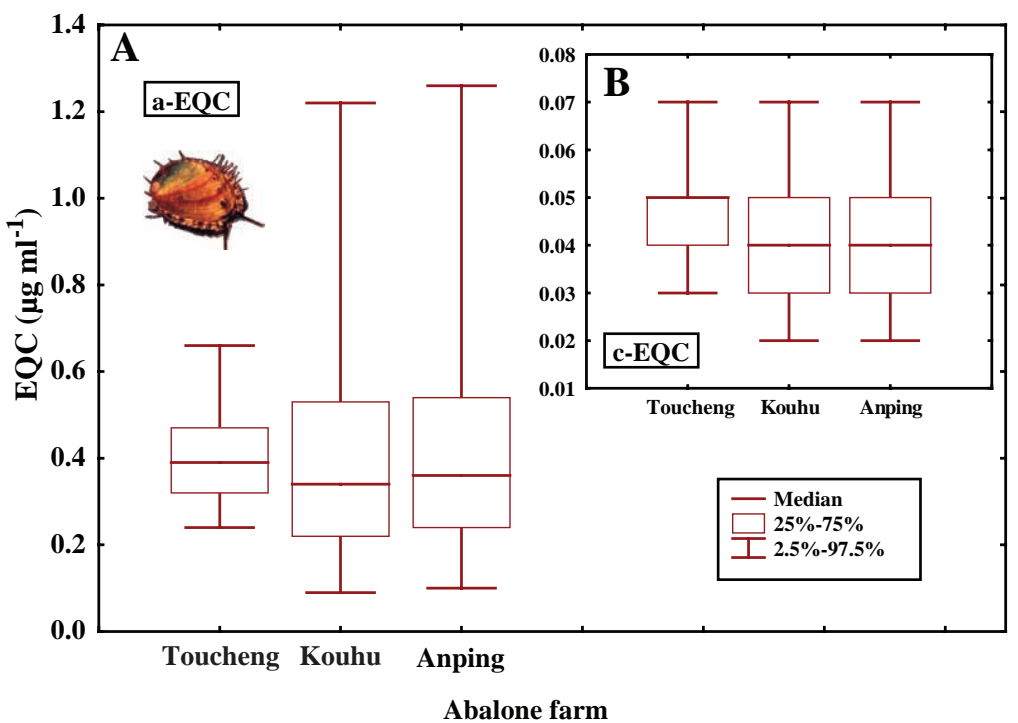

Fig. 5. Box and whisker plot representations of site-specific acute environmental quality criteria (a-EOC) and chronic EQC (c-EQC) for three selected abalone farms. Box and whisker plots are used to represent the uncertainty in EQC estimates.

Anping farms are $0.05,0.04$, and $0.04 \mu \mathrm{g} \mathrm{ml}^{-1}$, respectively (Fig. 5B), that are a little bit lower than the NOEC value of $0.0625 \mu \mathrm{g} \mathrm{ml}^{-1}$ (Tsai et al., 2004). The 97.5th-percentiles value of c-EQC for three abalone farms is $0.07 \mu \mathrm{g} \mathrm{ml}^{-1}$ which is a little bit higher than the chronic value of $0.088 \mu \mathrm{g} \mathrm{ml}^{-1}$ (Tsai et al., 2004).

The results of the sensitivity analyses on probabilistic EQC models are shown in the form of tornado plots illustrating the Spearman rank order correlation coefficients (Fig. 6). Sensitivity analyses reveal that model-derived site-specific a-EQC values are most sensitive to depuration rate constant $k_{2}(-73.3 \%)$ and IEC5 (48.6\%) in Toucheng farm, whereas to abalone biomagnification factor $\left(\mathrm{BMF}_{\mathrm{m}}\right)(73.7-77.1 \%)$ and IEC5/bioconcentration factor of algae $\left(\mathrm{BCF}_{\mathrm{a}}\right)(36 \%)$ in Kouhu and Anping farms (Fig. 6). The most important factor in the site-specific c-EQC model is the IEC5 (70\%) for all three abalone farms (Fig. 6).

\section{Discussion}

\subsection{Relationships between EEC and IEC}

We traditionally employed the environmental concentrations as the surrogate for the target organ concentrations to produce a given chemical effect to aquatic animals, e.g., LC50, LOEC, and NOEC. LC50based tests determine the EEC, although the observed effect depends on the intrinsic toxicity or biokinetic behavior of the chemical in the aquatic animal. Therefore, LC50-based parameters are mostly modeldependent, yet the models usually employed such as logit and probit have no biologically based assumptions that allow questions about the relevancy of such models. The current procedures in bioassays consist of observing lethality at fixed times, which can lead to the determination of LC50 endpoints, rather than survival curves. There is then a statistical dependence of LC50 data at consecutive times because they concern the same organisms. It is more robust and powerful to use the dose-time-response data than just the LC50 values. Survival models also consider raw experimental data as time to death versus concentration. They have an intrinsically greater statistically power, yet any biological interpretation is limited.

Recently, concept of the body residue hypothesis states that the use of environmental chemical concentrations to measure hazard could be misleading because the environmental concentration necessary to cause effect varies with the biouptake route, duration of exposure, type of exposure medium, and species used for testing (McCarty and Mackay, 1993). 
a-EQC

A

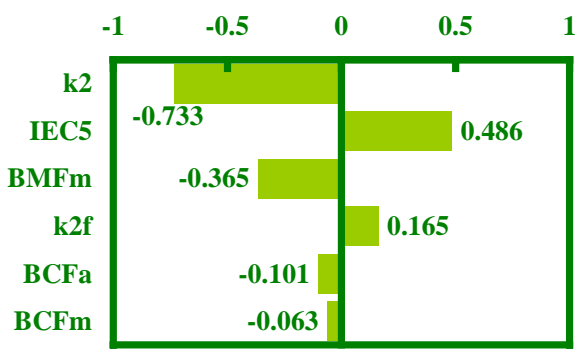

B

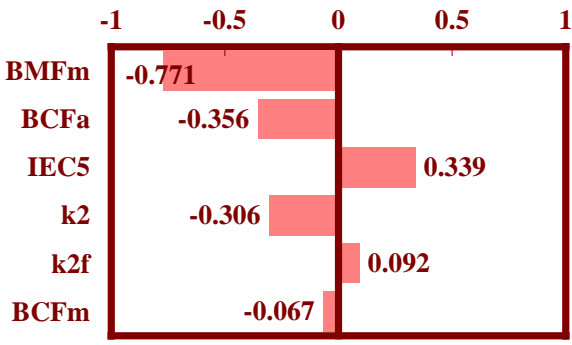

C

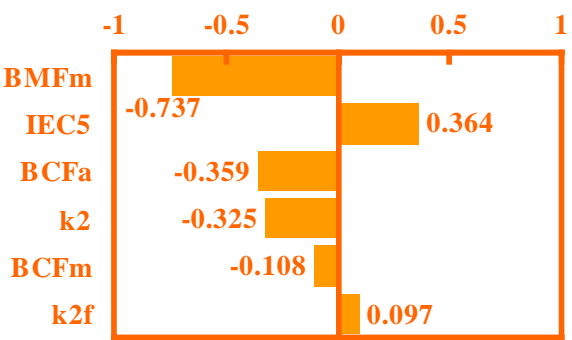

c-EQC
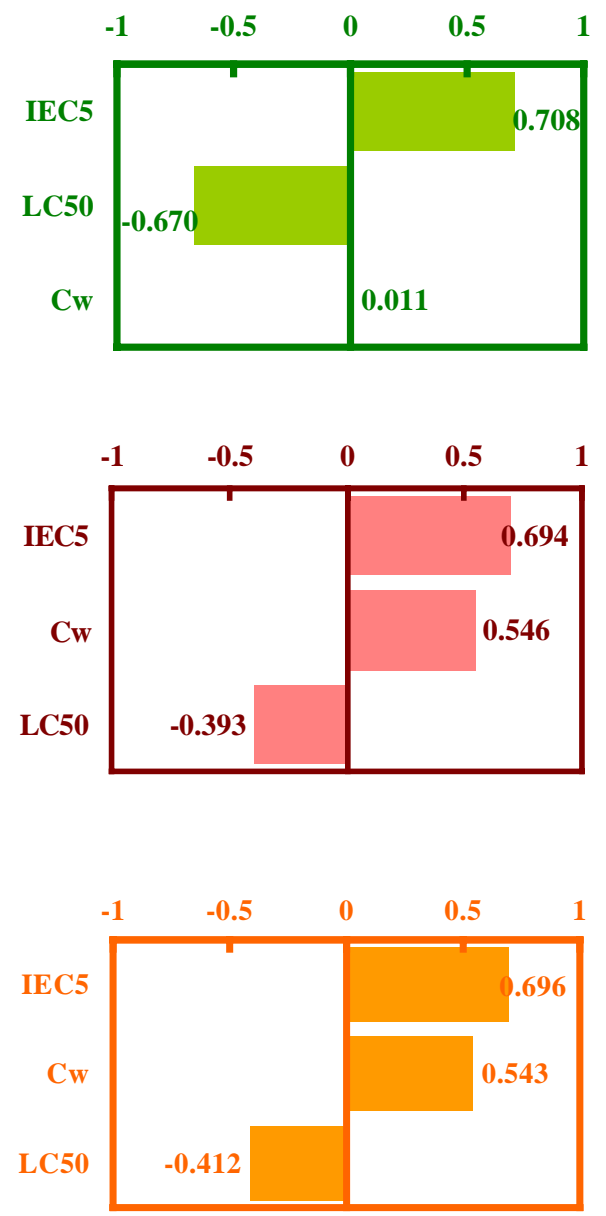

Fig. 6. Sensitivity analyses for probabilistic model-derived acute and chronic environmental quality criteria (a-EQC and c-EQC) for three selected abalone farms of (A) Toucheng, (B) Kouhu, and (C) Anping.

McCarty and Mackay (1993) and Sijm et al. (1993) further indicated that the chemical dose required to induce an effect at the target site in an organism should not change significantly with routes of exposure or duration, provided that the toxicity mechanism does not change and the injury dose does not accumulate over time. Thus, the use of dose-based estimates of effect (i.e., IEC) has the potential to eliminate variability due to changes in bioavailability, routes of exposure, and feeding type.

Based on toxicological principles, the mechanisms through which the dose at the target site elicits the ultimate adverse response are described by pharmacodynamic (PD) scheme and referred to as the action of the effect dose at the target site. McCarty and Mackay (1993) indicated that based on the receptor theory, many PD concepts and principles have their roots in a rather broad range of scientific endeavors. Verhaar et al. (1999) and Legierse et al. (1999) have developed a PD-based model to describe timedependent LC50 data, suggesting that PD-based model could be applied to regulate the acute toxicity and to estimate incipient LC50s and IECs of waterborne chemicals in organisms. 


\subsection{Significance of EQC for risk assessment}

In this work, a new method has developed to estimate the toxicity threshold for aquacultural animals. The method involves determining the IEC5 of the mortality endpoint from a reconstructed doseresponse model for farmed abalone and links to EEC5 by incorporating a CBR theory to determine a c-EQC for growth inhibition endpoint. These IEC5 and EEC5 can be appropriately transformed to concentration following the proposed predictive EQC equations at which no effects should be observed for mortality/ growth inhibition endpoints. The distributions can then be used as a surrogate for the NOEC or LOEC in risk assessment techniques, such as hazard quotient and probabilistic ecological risk assessment (Liao and Ling, 2004). This new method of estimating toxicity thresholds not only is more realistic than the use of arbitrary uncertainty factors but also is more conservative than current probabilistic risk assessment methods. In our analysis, we use a PD-based approach to reconstruct a dose-response curve for farmed abalone in order to estimate the IEC5 distribution. Therefore, the IEC5 is considered attractive because this parameter is a model-based value and the method is well established. We believe this to be a substantial improvement over reliance on a single NOEC or LOEC for the development of aquacultural water quality management. In our work, the use of a probabilistic analysis allows us to precisely state the level of protection that would be achieved. The method is easily adaptable if risk managers and the public desire more relaxed or stringent levels of protection.

The use of field-derived data in risk assessment is advantageous as it provides a more realistic estimate of toxicity as normal degradation and partitioning of toxicants can occur as compared to laboratory data, which can result in an overestimation of adverse impacts. By combining the field-derived parameters of $\mathrm{Zn}$ water concentrations and algae bioconcentration factor of $\mathrm{Zn}$ for establishing a predictive EQC models and using an estimated site-specific IEC5 distribution in the calculations of a-EQC and c-EQC, the risk assessor can be more confident that the proposed probabilistic model can become a first simple tool for regulatory applications until future research further verifies the model. We believe that the predictive EQC models with explicit threshold effect perform well than the hazard quotient model. The applications of the proposed model to real abalone farms give greatest support to a toxicity threshold relation among exceedence of metal criteria, the results of ambient bioassay, and aquacultural ecosystems. Furthermore, if a food web structure can be modeled in an aquacultural ecosystem based on established principles of bioaccumulation, we can employ food web model to calculate the corresponding concentration in water and sediment. In this way, generic EQC can be calculated for compounds for which we lack toxicity data.

\subsection{IECs in relation to mode of action}

Since $\mathrm{Zn}$ is an important essential nutrient in maintaining a wide variety of biological processes in organism, the total $\mathrm{Zn}$ content of tissues in abalone may not solely reflect to the toxic effect, mortality, of the metal. Therefore, the amount of required $\mathrm{Zn}$ at the target sites that causes mortality is expected to be higher than those of nonessential elements, indicating the idea of the LC50 value only gives the ambient concentration that causes toxicity, whereas the IECbased approach gives more accurate and comparable measure of the bioavailable concentration that actually reaches the target site(s) within the organism and causes toxic effect of mortality.

Recently, a Biotic Ligand Model (BLM) was developed to generate site-specific ambient water quality criteria for chronic $\mathrm{Zn}$ toxicity to juvenile rainbow trout (Oncorhynchus mykiss) (De Schamphelaere and Janssen, 2004) and acute $\mathrm{Zn}$ toxicity to Daphnia magna (Heijerick et al., 2002). The term "biotic ligand" refers to a discrete receptor or site of action on an organism where accumulation of metals leads to acutely toxic effects (Niyogi and Wood, 2004). It has been suggested that the binding tendencies of metals to ligands are conceptually linked to metal binding of biomolecules and consequent toxic effects (Niyogi and Wood, 2004). In spite of the models used in this study being applicable for metal toxicity prediction, nevertheless, to better assist accurate risk assessment posed by metals in aquacultural ecosystems, more studies and experimental data are needed to validate the applications of those models. 
Specifically, we have developed and characterized a site-specific EQC modeling framework that derives appropriate acute and chronic EQC for survival and growth of farmed abalone exposed to waterborne $\mathrm{Zn}$. As predicted by simple mathematical models, the IEC-based EQC can set a scientific standard in terms of bioaccumulation factors and acute-to-chronic value that is easily obtained for existed acute and chronic bioassay data. This probabilistic site-specific EQC modeling incorporating a mechanism involved in transport and biouptake of $\mathrm{Zn}$ in aquacultural ecosystems (e.g., BLM) allows us to account for receptorbased toxicity in dealing other modes of action based on different model concepts.

\section{Conclusions}

In this work, we use the IEC concept to develop EQC in a more integrated and efficient process in that we employ probabilistic methods to establish less subjective order-of-magnitude uncertainty factors in deriving EQC from limited empirical data. We also use the uncertainty analysis to estimate concentration that provides a specified level of protection (e.g., IEC5 and EEC5) for the high market prices aquacultural species. The results of field biomonitoring or field validation studies of proposed EQC should be used as evidence on the appropriateness of the proposed toxicity thresholds.

We believe that a probabilistic model-based framework is an effective representation of state-of-the-art results of scientific assessments for aquacultural species exposed to waterborne contaminants and has potential for use in EQC establishment. Despite great uncertainty in many aspects of integrated assessment, e.g., the problem of physical and chemical variables in water such as temperature, $\mathrm{pH}$, turbidity, oxygen level, which may modify the water metal concentrations, cautious interpretation of observations obtained from optimized-controlled laboratory can substantially reduce the likelihood.

Although the suitability and effectiveness of techniques for presenting uncertain results are context-dependent, we believe that such probabilistic methods are more valuable for communicating an accurate view of current scientific knowledge to those seeking information for decision-making than assess- ments that do not attempt to present results in probabilistic framework. We suggest that our probabilistic EQC modeling framework and methods be taken seriously because they produce general conclusions that are more robust than estimates made with a limited set of scenarios or without probabilistic presentations of outcomes, and our predictive EQC modeling technique highlights a risk-based framework in the future for better aquacultural ecosystem management.

\section{References}

Adams, W.J., Conard, B., Ethier, G., Brix, K.V., Paquin, P.R., Di Toro, D.M., 2000. The challenges of hazard identification and classification of insoluble metals and metal substances for the aquatic environment. Hum. Ecol. Risk Assess. 6, 1019-1038.

Arthur, J.W., Leonard, E.N., 1970. Effects of copper on Gammarus pseudolimnaeus, Physa integra, and Campeloma decisum in soft water. J. Fish. Res. Board Can. 27, 1277-1283.

Bergman, H.L., Dorward-King, E.J., 1997. Reassessment of Metals Criteria for Aquatic Life Protection. SETAC, Pensacola, FL, USA, pp. 1-81.

Chen, H.C., 1984. Studies on the aquaculture of small abalone, Haliotis diversicolor supertexta, in Taiwan. In: Liao, I.C., Hirano, R. (Eds.), Proceedings of ROC-Japan Symposium on Mariculture, vol. 1. Tungkang Marine Laboratory, Pintung, Taiwan, pp. $143-159$.

Chen, H.C., 1989. Farming the small abalone, Haliotis diversicolor supertexta, in Taiwan. In: Hahn, K.O. (Ed.), Handbook of Culture of Abalone and other Marine Gastropods. CRC Press, FL, USA, pp. 265-283.

Chen, J.C., Lee, W.C., 1999. Growth of Taiwan abalone Haliotis diversicolor supertexta fed on Gracilaria tenuistipitata and artificial diet in a multiple-tier basket system. J. Shellfish Res. $18,627-635$.

Conroy, P.T., Hunt, J.W., Anderson, B.S., 1996. Validation of a short-term toxicity test endpoint by comparison with longerterm effects on larval red abalone Holiotis rufescens. Environ. Toxicol. Chem. 15, 1245-1250.

De Schamphelaere, K.A.C., Janssen, C.R., 2004. Bioavailability and chronic toxicity of zinc to juvenile rainbow trout (Oncorhynchus mykiss) comparison with other fish species and development of a biotic ligand model. Environ. Sci. Technol. 38, 6200-6201.

Ford, L., 2001. Development of chronic aquatic water quality criteria and standards for silver. Water Environ. Res. 73, $248-253$.

Heijerick, D.G., De Schamphhelaere, A.C., Janssen, C.R., 2002. Prediction of acute zinc toxicity for Daphnia magna as a function of key water chemistry characteristics: development and validation of a biotic ligand model. Environ. Toxicol. Chem. 21, 1309-1315. 
Hughes, M.F., Heber, G.E., Morrison, S.C., Schimmel, S.C., Berry, W.J., 1989. An evaluation of a short-term chronic effluent toxicity test using sheepshead minnow (Cyprinodon variegates) larvae. Environ. Pollut. 60, 291-295.

Janssen, C.R., De Schamphelaere, K., Heijerick, D., Muyssen, B., Lock, K., Bossuyt, B., Vangheluwe, M., Van Sprang, P., 2000. Uncertainties in the environmental risk assessment of metals. Hum. Ecol. Risk Assess. 6, 1003-1018.

Knauer, K., Behra, R., Sigg, L., 1997. Effects of free $\mathrm{Cu}^{2+}$ and $\mathrm{Zn}^{2+}$ ions on growth and metal accumulation in freshwater algae. Environ. Toxicol. Chem. 16, 220-229.

Lee, C.L., Chen, H.Y., Chuang, M.Y., 1996. Use of oyster, Crassostrea gigas, and ambient water to assess metal pollution status of the Charting coastal area, Taiwan, after the 1986 green oyster incident. Chemosphere 33, 2505-2532.

Legierse, K.C.H.M., Verhaar, H.J.M., de Bruijn, J.H.M., Herman, J.L.M., 1999. Analysis of the time-dependent acute aquatic toxicity of organophosphorus pesticides: the critical target occupation model. Environ. Sci. Technol. 33, 917-925.

Liao, C.M., Lin, M.C., 2001. Acute toxicity modeling of rainbow trout and silver sea bream exposed to waterborne metals. Environ. Toxicol. 16, 349-360.

Liao, C.M., Ling, M.P., 2004. Probabilistic risk assessment of abalone Haliotis diversicolor supertexta exposed to waterborne zinc. Environ. Pollut. 127, 217-227.

Liao, C.M., Lin, M.C., Chen, J.S., Chen, J.W., 2002a. Linking biokinetics and consumer-resource dynamics of zinc accumulation in pond abalone Haliotis diversicolor supertexta. Water Res. 36, 5102-5112.

Liao, C.M., Chen, B.C., Lin, M.C., Chiu, H.M., Chou, Y.H., $2002 b$. Coupling toxicokinetics and pharmacodynamics for predicting survival of abalone (Haliotis diversicolor supertexta) exposed to waterborne zinc. Environ. Toxicol. 17, 478-486.

Liao, C.M., Ling, M.P., Chen, J.S., 2003. Appraising zinc bioaccumulation in abalone Haliotis diversicolor supertexta and alga Gracilaria tenuistipitata var. liui by probabilistic analysis. Aquaculture 217, 285-299.

Lin, M.C., Liao, C.M., 1999. ${ }^{65} \mathrm{Zn}$ (II) accumulation in the soft tissue and shell of abalone Haliotis diversicolor supertexta via the alga Gracilaria tenuistipitata var. liui and the ambient water. Aquaculture 178, 89-101.

McCarty, L.S., Mackay, D., 1993. Enhancing ecotoxicological modeling and assessment. Environ. Sci. Technol. 27, 1719-1728.

McGeer, J.C., Brix, K.V., Skeaff, J.M., De Forest, D.K., Brigham, S.I., Adams, W.J., Green, A.S., 2003. Inverse relationship between bioconcentration factor and exposure concentration for metals: implications for hazard assessment of metals in the aquatic environment. Environ. Toxicol. Chem. 22, 1017-1037.

Moore, D.R.J., Caux, P.Y., 1997. Estimating low toxic effects. Environ. Toxicol. Chem. 16, 794-801.
Niyogi, S., Wood, C.M., 2004. Biotic ligand model, a flexible tool for developing site-specific water quality guidelines for metals. Environ. Sci. Technol. 38, 6177-6192.

Richardson, C.A., 2001. Molluscs as archives of environmental change. Oceanogr. Mar. Biol. 39, 103-164.

Sijm, D.T.H.M., Schipper, M., Opperhuizen, A., 1993. Toxicokinetics of halogena ted benzenes in fish-lethal body burden as a toxicological end-point. Environ. Toxicol. Chem. 12, $1117-1127$.

Tsai, J.W., Chou, Y.H., Chen, B.C., Liao, C.M., 2004. Growth toxicity bioassays of abalone Halitois diversicolor supertexta exposed to waterborne zinc. Bull. Environ. Contam. Toxicol. 72, $70-77$.

Traas, T.P., van Wezel, A.P., Hermens, J.L.M., Zorn, M., van Hattum, A.G.M., van Leeuwen, C.J., 2004. Environmental quality criteria for organic chemicals predicted from internal effect concentrations and a food web model. Environ. Toxicol. Chem. 23, 2518-2527.

U.S. Environmental Protection Agency, 1985. Guidelines for Deriving Numerical National Water Quality Criteria for the Protection of Aquatic Organisms and their Uses. Off. Water, Washington, DC. NTIS-PB85-227049.

U.S. Environmental Protection Agency, 1995. Water Quality Criteria Documents for the Protection of Aquatic Life in Ambient Water. Office of Water, Washington, DC. EPA 820B-96-001.

Van der Brink, P.J., Brock, T.C.M., Posthuma, L., 2002. The value of the species-sensitivity distribution concept for predicting field effects (non-) confirmation using semifield experiments. In: Posthuma, L., Suter, G.W., Traas, T.P. (Eds.), Species Sensitivity Distributions in Ecotoxicology. Lewis, Boca Raton, FL, USA, pp. $155-193$.

Van der Hoeven, N., Noppert, F., Leopold, A., 1997. How to measure no effect: Part I. Towards a new measure of chronic toxicity in ecotoxicology. Introduction and workshop results. Environmetrics 8, 241-248.

Verhaar, H.J.M., de Wolf, W., Dyer, S., Legierse, K.C.H.M., Seinen, W., Herman, J.L.M., 1999. An LC50 vs. time model for the aquatic toxicity of reactive and receptor-mediated compounds. Consequences for bioconcentration kinetics and risk assessment. Environ. Sci. Technol. 33, 758-763.

Versteeg, D.J., Belanger, S.E., Carr, G.J., 1999. Understanding single-species and model ecosystem sensitivity: data-based comparison. Environ. Toxicol. Chem. 18, 1329-1346.

Wang, W.X., Ke, C.H., 2002. Dominance of dietary intake of cadmium and zinc by two marine predatory gastropods. Aquat. Toxicol. 56, 153-165.

Weiss, J.N., 1997. The Hill equation revisited: uses and misuses. FASEB J. 11, 835-841. 